\title{
Effectiveness of meglumine antimoniate against L. tropica in a recently emerged focus of cutaneous leishmaniasis in Birjand, eastern Islamic Republic of Iran
}

M. Karamian, ${ }^{1}$ M.S. Faroghi Bojd, ${ }^{2}$ A. Salehabadi, ${ }^{3}$ M. Hemmati ${ }^{4}$ and D.A. Barati ${ }^{2}$

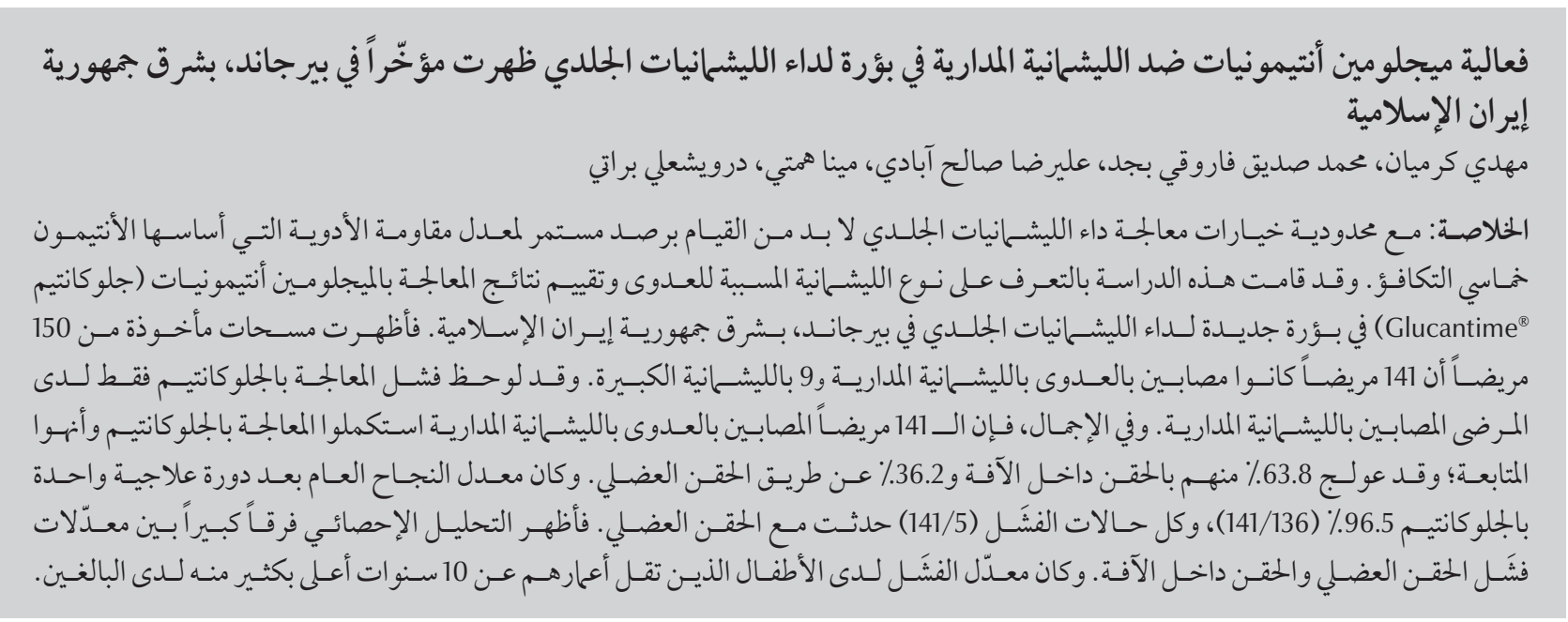

ABSTRACT With limited options to treat cutaneous leishmaniasis, constant monitoring of the rate of resistance to pentavalent antimony-based drugs is needed. This study identified the infecting Leishmania species and evaluated the results of meglumine antimoniate (Glucantime ${ }^{\circledR}$ ) therapy in a new focus of cutaneous leishmaniasis in Birjand, eastern Islamic Republic of Iran. Smears from 150 patients showed that 141 patients were infected by L. tropica and 9 by L. major. In total, 141 patients with L. tropica infection completed Glucantime ${ }^{\circledR}$ treatment and follow-up; $63.8 \%$ were treated intralesionally and $36.2 \%$ by intramuscular administration. The overall success rate after one course of therapy with Glucantime was $96.5 \%$ (136/141), and all the failures (5/141) occurred with intramuscular injections. Statistical analysis showed a significant difference between the failure rates of intramuscular and intralesional injections. Children $<10$ years old had a significantly higher failure rate than adults.

Efficacité de l'antimoniate de méglumine contre Leishmania tropica dans un nouveau foyer émergent de leishmaniose cutanée à Birjand, dans l'est de la République islamique d'Iran

RÉSUMÉ Les options thérapeutiques pour la leishmaniose cutanée étant limitées, une surveillance constante du taux de résistance aux médicaments à base d'antimoine pentavalent est nécessaire. La présente étude a identifié les espèces infectantes de Leishmania et a évalué les résultats d'un traitement par antimoniate de méglumine (Glucantime ${ }^{\circledR}$ ) dans un nouveau foyer de leishmaniose cutanée à Birjand, dans l'est de la République islamique d'Iran. Les frottis de 150 patients ont révélé que 141 patients étaient infectés par L. tropica et 9 patients par L. major. Au total, 141 patients infectés par L. tropica ont achevé le traitement par Glucantime ${ }^{\circledR}$ et sont allés jusqu'au bout du suivi ; 63,8 \% ont reçu un traitement intralésionnel et 36,2\% une injection intramusculaire. Le taux de succès global après un traitement par Glucantime ${ }^{\circledR}$ était de $96,5 \%$ (136/141), et tous les échecs (5/141) ont été observés chez les patients ayant reçu des injections intramusculaires. L'analyse statistique a mis en évidence une différence significative des taux d'échec entre les injections intramusculaires et les injections intralésionnelles. Le taux d'échec chez les enfants de moins de dix ans était supérieur à celui observé chez les adultes. 


\section{Introduction}

Cutaneous leishmaniasis is a public health concern in more than 70 countries across the world. It can be caused by several Leishmania spp. and is transmitted to human beings and animals via sandflies (1). More than $90 \%$ of the world's cases of cutaneous leishmaniasis occur in only a few countries: Afghanistan, Algeria, Islamic Republic of Iran, Iraq, Saudi Arabia and Syrian Arab Republic in the Old World; and Bolivia, Brazil, Colombia, Nicaragua and Peru in the New World (2).

In the Islamic Republic of Iran the disease is endemic to over $50 \%$ of provinces (3), with Leishmania major and L. tropica being the primary agents of zoonotic cutaneous leishmaniasis and anthroponotic cutaneous leishmaniasis respectively (4). Anthroponotic cutaneous leishmaniasis caused by L. tropica, which tends to be more problematic for both diagnosis and treatment and lasts longer than infections caused by $L$. major (5), is mainly reported in urban areas of central, north east and southeast of the Islamic Republic of Iran (6). The main reservoir host of L. tropica is humans, and Phlebotomus sergenti is considered as main vector of anthroponotic cutaneous leishmaniasis in the country (7).

Birjand, the centre of South Khorasan province, is located in the eastern part of the country. In past years sporadic cases of cutaneous leishmaniasis have been diagnosed in Birjand county, but it was thought that they were imported cases from neighbouring endemic areas. Studies of increased number of cases, however, have revealed that an endemic focus of cutaneous leishmaniasis formed around 2008 and since then an annual average of 50 cases have been reported in the region. The region has a population of about 200000 people.

The pentavalent antimonybased drugs meglumine antimoniate
(Glucantime ${ }^{\circ}$ ) and sodium stibogluconate (Pentostam ${ }^{\circ}$, GlaxoWellcome) or generic sodium stibogluconate (Albert David Ltd, India) are the first line of treatment against both New World and Old World types of cutaneous leishmaniasis $(8-10)$. However, increasing resistance of Leishmania spp. to these compounds has limited their usefulness in this context (11). Glucantime is a commonly used pentavalent antimony-based drug for the treatment of visceral and cutaneous leishmaniasis in the Islamic Republic of Iran. However, in recent years, cases of glucantimeresistant $L$. tropica have been reported in unresponsive cutaneous leishmaniasis patients (12).

Because of the limited options for alternatives to treat cutaneous leishmaniasis and given that this is an endemic disease in different locations throughout the Islamic Republic of Iran, constant monitoring of the incidence of resistance to these compounds is necessary (13). The objective of this study was to assess the effectiveness of meglumine antimoniate on patients infected by L. tropica in this new focus of cutaneous leishmaniasis.

\section{Methods}

\section{Study area and population}

The study was conducted from April 2008 to March 2012 in Bijand county of Southern Khorasan province in the eastern part of the Islamic Republic of Iran. All patients selected for the study were living in Birjand and its subsidiary villages, a region of approximately $6700 \mathrm{~km}^{2}$ (Figure 1). This region has a cold desert climate with hot summers and cool winters. This area altitude ranges between 1250 and $2050 \mathrm{~m}$ above sea level. The city has a dry climate with a significant difference between day and night temperatures. The average annual high and low temperatures are $25^{\circ} \mathrm{C}$ and $8.5^{\circ} \mathrm{C}$ respectively. The average annual rainfall is $170 \mathrm{~mm}$. This region is the largest producer of saffron and barberries in the country.

A total of 188 parasitologically new confirmed cases of cutaneous leishmaniasis (i.e. Giemsa-stained smear-positive cases) who were referred to the city health centre of Birjand were recruited for this study. Of these, 154 completed the antimonial treatment course and follow-up. Out of these patients, 4 with previous treatment of cutaneous leishmaniasis were excluded from the study.

The study was approved by the ethics review committee of Birjand University of Medical Sciences.

\section{Data collection}

\section{Collection of samples}

Microscopic examination of Giemsastained scrapings taken from the margins of skin lesions of patients was used for diagnosis of cutaneous leishmaniasis. A questionnaire was completed for each case to record information about name, age, sex, number of lesions, patient's address, date and place of acquiring the disease, lesion sites and duration, work place and travel history.

\section{PCR-RFLP}

The dermal scrapings of the patients were used to identify species of causative agents by polymerase chain reaction (PCR) assay. DNA was purified for PCR using an AccuPrep ${ }^{\circ}$ genomic DNA extraction kit (Bioneer) according to the manufacturer's instruction. Species-specific primers, LITSR (forward, 5'-CTG GAT CAT TTT CCG ATG-3') and L5.8S (reverse, 5'-TGA TAC CAC TTA TCG CAC TГ-3') were carried out as described by Schonian et al. to amplify the ITS1 region of the Leishmania ribosomal DNA (14). The PCR product of ITS1 was subjected to restriction fragment length polymorphism (RFLP) analysis by digesting the PCR amplified product with BsuRI (Fermentas), a HaeIII prototype, according to the manufacturer's 


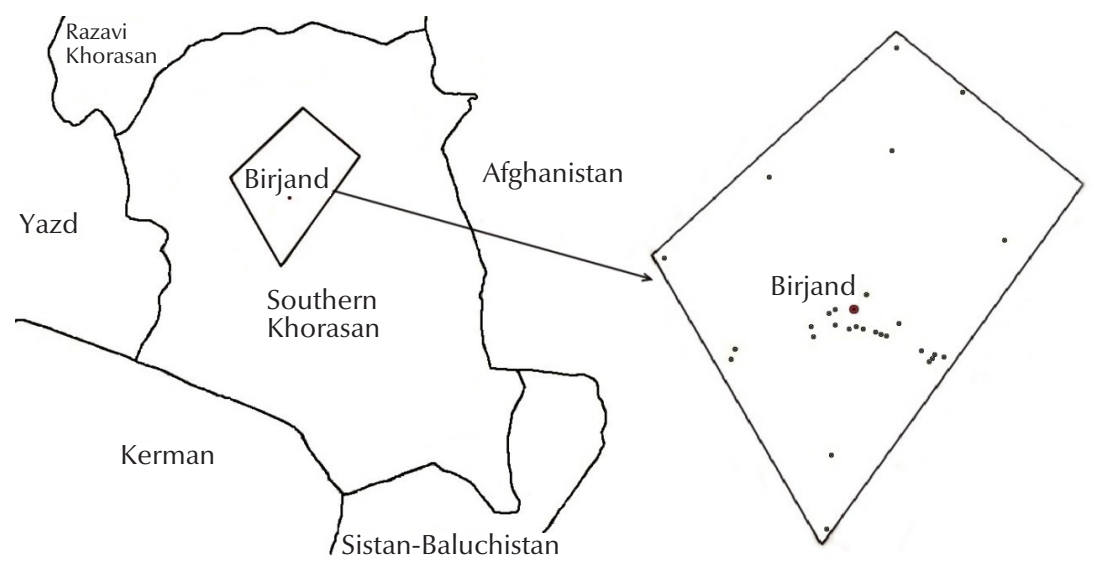

Figure 1 Geographical distribution of patients with cutaneous leishmaniasis in Birjand and its villages, southern Khorasan, Islamic Republic of Iran, 2008-2012

instructions (15). The restriction fragments were analysed on $2 \%$ agarose gel by electrophoresis and visualized under ultraviolet light after being stained with ethidium bromide.

\section{Treatment}

Patients were divided into 2 treatment groups: intramuscular versus intralesional administration of Glucantime ${ }^{\circledast}$. Patients with $\leq 3$ lesions and/or lesions $<3 \mathrm{~cm}$ in diameter were treated with Glucantime intralesionally if the lesions were not: located on the face or neck or over the joints, sporotrichoid or superinfected with bacteria (13). Among 141 patients with L. tropica, 51 were injected intramuscular with Glucantime ${ }^{\bullet}$, while 90 patients were treated intralesionally. Intralesional Glucantime ${ }^{\circledR}$ (Aventis; containing $81 \mathrm{mg}$ antimony $/ \mathrm{mL}$ ) was injected intradermally $(0.5-1 \mathrm{~mL}$ per lesion per week, depending on the size) in each lesion from all directions until the lesion was completely blanched (16). This treatment was carried out once per week until there was complete healing of the ulcer or for a maximum of 12 weeks.

All other patients were prescribed intramuscular Glucantime ${ }^{\star}$ at $20 \mathrm{mg} /$ $\mathrm{kg} /$ day for 20 days according to the national guidelines distributed by the Iranian Centre for Disease Control. However, after the 10th day of intramuscular therapy, treatment was discontinued if there were increases in liver enzymes, blood urea nitrogen, creatinine or skin reactions at the injection site.

Patients who had no indications for therapy, pregnant and lactating women and those with underlying conditions (cardiac and renal diseases, etc.) were excluded from Glucantime ${ }^{\circledast}$ therapy. Healing of the cutaneous lesions was evaluated clinically and confirmed by preparation of direct smears. Successful treatment was defined as complete re-epithelialization of all lesions with no recurrence within 6 months of follow-up.

\section{Statistical analysis}

The data were analysed using Fisher exact test using SPSS, version 16 software. A $P$-value of $<0.05$ was considered statistically significant.

\section{Results}

A total of 150 patients with cutaneous leishmaniasis entered the study. A review of the medical records of the patients showed that most of them were infected in or near their residence in Birjand county and did not stay in an endemic region of cutaneous leishmaniasis during the infection period. The majority of patients were referred to the city health centre in the autumn and winter. The lesions had been present for an average of 108 days and the mean number of lesions was 1.75 .

Species identification of Leishmania spp. in the patients' smears using PCRRFLP of the ITS1 rDNA showed that 141 patients had L. tropica and 9 others were infected by L. major. There was no statistically significant relationship between the clinical features of the cases and the infecting Leishmania spp. ( $\mathrm{Ta}-$ ble 1). The overall success rate after one course of therapy with Glucantime was 96.5\% (136/141) in L. tropica cases and $100 \%$ in patients infected by L. major (Table 1).

Because of the low number of patients with $L$. major infection, and given the healing process of L. major lesions may be shorter than the 6 months follow-up period, only L. tropica-infected patients were included in the follow-up and analysis of factors associated with cure or failure.

\section{Factors associated with cure in cases with L. tropica}

A total of 90 L. tropica cases (63.8\%) were treated intralesionally and $51 \mathrm{pa}-$ tients $(36.2 \%)$ were treated intramuscularly (Table 2). During the treatment follow-up period, 136 patients showed a positive response to treatment, so the overall success rate of $L$. tropica-infected patients who received one course of Glucantime ${ }^{\circ}$ was $96.5 \%$. On the other hand, cutaneous lesions did not heal in 5 others until the end of the follow-up period.

All the 5 treatment failures occurred in the cases of intramuscular injection of Glucantime and thus the failure rate among patients having intramuscular injections was 9.8\% (5/51) versus none of the intralesionally treated cases. Statistical analysis showed a significant difference between the failure rates of intralesional and intramuscular injections $(P=0.005)$. 


\begin{tabular}{|c|c|c|c|c|c|}
\hline \multirow[t]{2}{*}{ Variable } & \multicolumn{2}{|c|}{$\begin{array}{c}\text { L. tropica } \\
(n=141)\end{array}$} & \multicolumn{2}{|c|}{$\begin{array}{l}\text { L. major } \\
\qquad(n=9)\end{array}$} & \multirow[t]{2}{*}{$P$-value ${ }^{\text {a }}$} \\
\hline & No. & $\%$ & No. & $\%$ & \\
\hline \multicolumn{6}{|l|}{ Sex } \\
\hline Male & 76 & 53.9 & 4 & 44.4 & \multirow[t]{2}{*}{0.734} \\
\hline Female & 65 & 46.1 & 5 & 55.6 & \\
\hline \multicolumn{6}{|l|}{ Age group (years) } \\
\hline$<10$ & 32 & 22.7 & 1 & 11.1 & \multirow[t]{2}{*}{0.684} \\
\hline$\geq 10$ & 109 & 77.3 & 8 & 88.9 & \\
\hline \multicolumn{6}{|l|}{ Residency } \\
\hline Urban & 93 & 66.0 & 6 & 66.7 & \multirow[t]{2}{*}{1.0} \\
\hline Rural & 48 & 34.0 & 3 & 33.3 & \\
\hline \multicolumn{6}{|l|}{ No. oflesions } \\
\hline$\leq 3$ & 130 & 92.2 & 7 & 77.8 & \multirow[t]{2}{*}{0.176} \\
\hline$>3$ & 11 & 7.8 & 2 & 22.2 & \\
\hline \multicolumn{6}{|l|}{ Location oflesions } \\
\hline Face and neck & 45 & 31.9 & 2 & 22.2 & \multirow[t]{3}{*}{0.807} \\
\hline Extremities & 90 & 63.8 & 7 & 77.8 & \\
\hline Both & 6 & 4.3 & 0 & 0.0 & \\
\hline \multicolumn{6}{|c|}{ Response to Glucantime ${ }^{\circledast}$} \\
\hline Cure & 136 & 96.5 & 9 & 100.0 & \multirow[t]{2}{*}{1.0} \\
\hline Failure & 5 & 3.5 & 0 & 0.0 & \\
\hline
\end{tabular}

${ }^{a}$ Fisher exact test.

There was also a statistically significant difference in the cure rate by intramuscular administration of Glucantime $^{\circ}$ between the 2 patient age groups $(P<0.05)$; patients $<10$ years old had a lower cure rate $(77.8 \%)$ than older patients (97.0\%). The overall cure rate of Glucantime therapy was significantly lower in patients $<10$ years old $(P<0.01)$ (Table 2).

In addition, the results showed that the number of lesions per patient was associated with response to treatment. In patients with $>3$ lesions, the cure rate was significantly lower than those with fewer lesions $(81.8 \%$ versus $97.7 \%)(P<0.05)$ (Table 2). But there was no significant correlation between the improvement rate and the sex of the patients, location of the lesions, duration of therapy and patients' residency.

The maximum number of full reepithelializations oflesions was seen within 3 months after the start of treatment.

\section{Discussion}

Monitoring resistance to pentavalent antimonials, which are the first-line treatment of cutaneous leishmaniasis, is necessary (17). This has become more important in the new endemic foci of cutaneous leishmaniasis such as Birjand county. In the present study, the overall success rate after one course of therapy with Glucantime administered either intralesionally or intramuscularly was $96.5 \%(136 / 141)$. While the success rate of intralesional injection of the drug (maximum 12 weeks) was $100 \%$, the intramuscular treatment of cutaneous leishmaniasis had a lower success rate of $90.2 \%(46 / 51)$. A wide range of success has been reported for intralesional injection of Glucantime in other investigations conducted in the Islamic Republic of Iran $(13,18,19)$. Unfortunately, in most of those studies the species of Leishmania was not identified, and there were variations in treatment courses.

Different values have been reported as success rates for one course of standard intramuscular Glucantime in patients treated with $20 \mathrm{mg} / \mathrm{kg} /$ day in endemic areas of cutaneous leishmaniasis in the Islamic Republic of Iran. In studies conducted in the southern and northern parts of the country on patients infected by L. major, the rate of treatment success was $65.1 \%$ and $83.3 \%$ respectively $(9,20)$. In 2 other investigations which were done in the central provinces of the country, intramuscular treatment by Glucantime ${ }^{\circ}$ had success rates of $75.8 \%$ (13) and 93.0\% respectively (21), although the causative agents of the disease were not identified. In another study in the eastern area, which included cutaneous leishmaniasis patients infected by L. tropica, intramuscular injection of Glucantime ${ }^{\circ}$ had a success rate at $95.3 \%$ 


\begin{tabular}{|c|c|c|c|c|c|}
\hline \multirow[t]{2}{*}{ Variable } & \multicolumn{2}{|c|}{ Cure } & \multicolumn{2}{|c|}{ Failure } & \multirow[t]{2}{*}{$P$-value } \\
\hline & No. & $\%$ & No. & $\%$ & \\
\hline \multicolumn{6}{|l|}{ Sex } \\
\hline Male & 74 & 97.4 & 2 & 2.6 & \multirow[t]{2}{*}{0.662} \\
\hline Female & 62 & 95.4 & 3 & 4.6 & \\
\hline \multicolumn{6}{|l|}{ Age group (years) } \\
\hline$<10$ & 28 & 87.5 & 4 & 12.5 & \multirow[t]{2}{*}{0.01} \\
\hline$\geq 10$ & 108 & 99.1 & 1 & 0.9 & \\
\hline \multicolumn{6}{|l|}{ Type of injection } \\
\hline Intramuscular & 46 & 90.2 & 5 & 9.8 & \multirow[t]{2}{*}{0.005} \\
\hline Intralesional & 90 & 100.0 & 0 & 0.0 & \\
\hline \multicolumn{6}{|c|}{ Intramuscular injection by age group (years) } \\
\hline$<10$ & 13 & 77.8 & 4 & 22.2 & \multirow[t]{2}{*}{0.037} \\
\hline$\geq 10$ & 33 & 97.0 & 1 & 3.0 & \\
\hline \multicolumn{6}{|c|}{ Duration of intramuscular- therapy (days) } \\
\hline$<10$ & 1 & 100.0 & 0 & 0.0 & \multirow[t]{3}{*}{0.416} \\
\hline $10-14$ & 3 & 75.0 & 1 & 25.0 & \\
\hline$\geq 15$ & 42 & 91.3 & 4 & 8.7 & \\
\hline \multicolumn{6}{|c|}{ No. of intralesional injections } \\
\hline $1-4$ & 5 & 100.0 & 0 & 0.0 & \multirow[t]{3}{*}{1.0} \\
\hline $5-8$ & 18 & 100.0 & 0 & 0.0 & \\
\hline $9-12$ & 118 & 100.0 & 0 & 0.0 & \\
\hline \multicolumn{6}{|l|}{ No. of lesions } \\
\hline$\leq 3$ & 127 & 97.7 & 3 & 2.3 & \multirow[t]{2}{*}{0.049} \\
\hline$>3$ & 9 & 81.8 & 2 & 18.2 & \\
\hline \multicolumn{6}{|l|}{ Location of lesions } \\
\hline Face and neck & 42 & 93.3 & 3 & 6.7 & \multirow[t]{3}{*}{0.465} \\
\hline Extremities & 88 & 97.8 & 2 & 2.2 & \\
\hline Both & 6 & 100.0 & 0 & 0.0 & \\
\hline \multicolumn{6}{|l|}{ Residency } \\
\hline Urban & 89 & 95.7 & 4 & 4.3 & \multirow[t]{2}{*}{0.661} \\
\hline Rural & 47 & 97.9 & 1 & 2.1 & \\
\hline
\end{tabular}

${ }^{a}$ Fisher exact test.

(12). So the efficacy of treatment with intramuscular injection of Glucantime ${ }^{\circ}$ in the present study is consistent with the survey conducted in eastern Islamic Republic of Iran.

Comparison of response rates between the 2 age groups of the patients ( $<$ and $\geq 10$ years of age) revealed that the cure rate of intramuscular Glucantime $^{\circ}$ was significantly lower in children $<10$ years of age $(P<0.05)$. A number of other studies have yielded similar results. Layegh et al. showed that systemic Glucantime has a significantly lower efficacy in treating acute cutaneous leishmaniasis in children than in adults (22). In another study performed on L. viannia species, cutaneous treatment by systemic Glucantime also had a clinically significant lower response in children when compared with the same regimen dosage and duration in adults (23). Several reasons for this have been proposed: a weaker immune response in children, differences in the pharmacokinetics of the drug in different age groups and differences in exposure to parasite antigens and sandfly saliva (24).

The cure rate of intralesional therapy in our study was significantly higher than intramuscular therapy. In the study by Alkhawajah and Larbi intralesional treatment method also has better results compared with intramuscular Glucantime ${ }^{\circ}$, although there was no statistically significant difference between the 2 routes of administration (25). Uzun et al. obtained a high cure rate (97.2\%) of cutaneous leishmaniasis by intralesional 
injection of Pentostam ${ }^{\circledR}$, another pentavalent antimonial agent (26).

Patients with $>3$ lesions had significantly higher failure rate than the patients with fewer lesions $(P<0.05)$. This may have resulted from the significantly higher percentage of intramuscular versus intralesional Glucantime in patients with $>3$ lesions $(P<0.05)$. Sex, location of lesions, self-reported previous treatment with Glucantime ${ }^{\varpi}$ and patients' residency (urban/rural) had no effect on the response rate to the treatment.

Identification of causative agents of cutaneous leishmaniasis using an ITS1 PCR-RFLP assay showed that all the patients with no response to treatment in this study were infected by L. tropica. In contrast, no treatment failures were observed in the patients who identified as being infected by L. major.

\section{Conclusion}

In conclusion, we found a higher rate of success with standard Glucantime therapy than other studies conducted in the Islamic Republic of Iran. Furthermore, the study results indicated that systemic treatment with meglumine antimoniate was less successful in children compared with adults. We recommend further research to evaluate the efficacy of cutaneous leishmaniasis drugs due to the differences in pathogenesis and treatment processes between these agents.

\section{Acknowledgements}

We wish to thank the Vice Chancellor for Research of Birjand University of Medical Science and the authorities of Birjand city health centre.

\section{Funding: None.}

Competing interests: None declared.

\section{References}

1. Reithinger R, Dujardin JC, Louzir H, Pirmez C, Alexander B, Brooker S. Cutaneous leishmaniasis. Lancet Infect Dis. 2007 Sep;7(9):581-96. PMID:17714672

2. Chapter 3. In: Herwaldt BL, Magill AJ. Leishmaniasis, cutaneous. CDC health information for international travel 2014 Oxford: Oxford University Press; 2013.

3. Khosravi A, Sharifi I, Dortaj E, Aghaei Afshar A, Mostafavi M The present status of cutaneous leishmaniasis in a recently emerged focus in South-west of Kerman province, Iran. Iran J Public Health. 2013;42(2):182-7. PMID:23515397

4. Nadim A, Seyedi-Rashti MA. A brief review of the epidemiology of various types of leishmaniases in Iran. Acta Med Iran. 1971;14:99-106.

5. Ajdary S, Riazi-Rad F, Alimohammadian MH, Pakzad SR. Immune response to Leishmania antigen in anthroponotic cutaneous leishmaniasis. J Infect. 2009 Aug;59(2):139-43. PMID:19560211

6. Shahbazi F, Shahabi S, Kazemi B, Mohebali M, Abadi AR, Zare Z. Evaluation of PCR assay in diagnosis and identification of cutaneous leishmaniasis: a comparison with the parasitological methods. Parasitol Res. 2008 Oct;103(5):1159-62. PMID:18651180

7. Afshar AA, Rassi Y, Sharifi I, Abai M, Oshaghi M, YaghoobiErshadi M, et al. Susceptibility status of Phlebotomus papatasi and P. sergenti (diptera: psychodidae) to DDT and deltamethrin in a focus of cutaneous leishmaniasis after earthquake strike in Bam, Iran. Iran J Arthropod Borne Dis. 2011;5(2):32-41. PMID:22808416

8. Negera E, Gadisa E, Hussein J, Engers H, Kuru T, Gedamu L, et al. Treatment response of cutaneous leishmaniasis due to Leishmania aethiopica to cryotherapy and generic sodium stibogluconate from patients in Silti, Ethiopia. Trans R Soc Trop Med Hyg. 2012 Aug;106(8):496-503. PMID:22503475

9. Pourmohammadi B, Motazedian MH, Handjani F, Hatam $\mathrm{GH}$, Habibi S, Sarkari B. Glucantime efficacy in the treatment of zoonotic cutaneous leishmaniasis. Southeast Asian J Trop Med Public Health. 2011 May;42(3):502-8. PMID:21706927

10. Romero GA, Molinet FJ, Noronha EF. Early enlargement of an ulcerated area during leishmaniasis treatment with meglumine antimoniate in Brazil. Trans R Soc Trop Med Hyg. 2013 Apr;107(4):266-8. PMID:23315614
11. Aït-Oudhia K, Gazanion E, Vergnes B, Oury B, Sereno D. Leishmania antimony resistance: what we know what we can learn from the field. Parasitol Res. 2011 Nov;109(5):1225-32. PMID:21800124

12. Hadighi R, Mohebali M, Boucher P, Hajjaran H, Khamesipour A, Ouellette M. Unresponsiveness to Glucantime treatment in Iranian cutaneous leishmaniasis due to drugresistant Leishmania tropica parasites. PLoS Med. 2006 May;3(5):e162. PMID:16605301

13. Mohammadzadeh M, Behnaz F, Golshan Z. Efficacy of glucantime for treatment of cutaneous leishmaniasis in central Iran. J Infect Public Health. 2013 Apr;6(2):120-4. PMID:23537825

14. Schönian G, Nasereddin A, Dinse N, Schweynoch C, Schallig HD, Presber W, et al. PCR diagnosis and characterization of Leishmania in local and imported clinical samples. Diagn Microbiol Infect Dis. 2003 Sep;47(1):349-58. PMID:12967749

15. Bensoussan E, Nasereddin A, Jonas F, Schnur LF, Jaffe CL. Comparison of PCR assays for diagnosis of cutaneous leishmaniasis. J Clin Microbiol. 2006 Apr;44(4):1435-9. PMID:16597873

16. Shamsi Meymandi S, Zandi S, Aghaie H, Heshmatkhah A. Efficacy of $\mathrm{CO}(2)$ laser for treatment of anthroponotic cutaneous leishmaniasis, compared with combination of cryotherapy and intralesional meglumine antimoniate. J Eur Acad Dermatol Venereol. 2011 May;25(5):587-91. PMID:20666876

17. Croft SL, Sundar S, Fairlamb AH. Drug resistance in leishmaniasis. Clin Microbiol Rev. 2006 Jan;19(1):111-26. PMID:16418526

18. Khatami A, Talaee R, Rahshenas M, Khamesipour A, Mehryan $P$, Tehrani S, et al.. Dressings combined with injection of meglumine antimoniate in the treatment of cutaneous leishmaniasis: a randomized controlled clinical trial. PLoS One. 2013 Jun 24;8(6):e6612. PMID:23826087

19. Maleki M, Karimi G, Tafaghodi M, Raftari S, Nahidi Y. Comparison of intralesional two percent zinc sulfate and glucantime injection in treatment of acute cutaneous leishmaniasis. Indian J Dermatol. 2012 Mar;57(2):118-22. PMID:22615508

20. Mohebali M, Fotouhi A, Hooshmand B, Zarei Z, Akhoundi $B$, Rahnema A, et al. Comparison of miltefosine and meglumine antimoniate for the treatment of zoonotic cutaneous 
leishmaniasis ( $\mathrm{ZCL}$ ) by a randomized clinical trial in Iran. Acta Trop. 2007 Jul;103(1):33-40. PMID:17586452

21. Nilforoushzadeh MA, Jaffary F, Ansari N, Siadat AH, Nilforoushan Z, Firouz A. A comparative study between the efficacy of systemic meglumine antimoniate therapy with standard or low dose plus oral omeprazole in the treatment of cutaneous leishmaniasis. J Vector Borne Dis. 2008 Dec;45(4):287-91. PMID:19248655

22. Layegh P, Rahsepar S, Rahsepar AA. Systemic meglumine antimoniate in acute cutaneous leishmaniasis: children versus adults. Am J Trop Med Hyg. 2011 Apr;84(4):539-42. PMID:21460006

23. Cruz A, Rainey PM, Herwaldt BL, Stagni G, Palacios R, Trujillo $\mathrm{R}$, et al. Pharmacokinetics of antimony in children treated for leishmaniasis with meglumine antimoniate. J Infect Dis. 2007 Feb 15;195(4):602-8. PMID:17230422
24. Llanos-Cuentas A, Tulliano G, Araujo-Castillo R, MirandaVerastegui C, Santamaria-Castrellon G, Ramirez L, et al. Clini$\mathrm{cal}$ and parasite species risk factors for pentavalent antimonial treatment failure in cutaneous leishmaniasis in Peru. Clin Infect Dis. 2008 Jan 15;46(2):223-31. PMID:18171254

25. Alkhawajah AM, Larbi E, al-Gindan $\mathrm{Y}$, Abahussein A, Jain $\mathrm{S}$. Treatment of cutaneous leishmaniasis with antimony: intramuscular versus intralesional administration. Ann Trop Med Parasitol. 1997 Dec;91(8):899-905. PMID:9579209

26. Uzun S, Durdu M, Culha G, Allahverdiyev AM, Memisoglu HR. Clinical features, epidemiology, and efficacy and safety of intralesional antimony treatment of cutaneous leishmaniasis: recent experience in Turkey. J Parasitol. 2004 Aug;90(4):853-9. PMID:15357081 